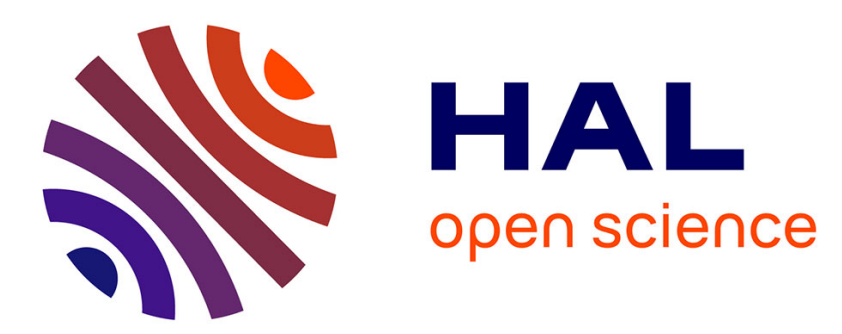

\title{
Nonempirical Kinetic Modeling of Non-fickian Water Absorption Induced by a Chemical Reaction in Epoxy-Amine Networks
}

Xavier Colin

\section{- To cite this version: \\ Xavier Colin. Nonempirical Kinetic Modeling of Non-fickian Water Absorption Induced by a Chemical Reaction in Epoxy-Amine Networks. Solid Mechanics and Its Applications, 2, Springer, pp.1-18, 2018, 978-3-319-65144-6. 10.1007/978-3-319-65145-3_1. hal-02592046}

\section{HAL Id: hal-02592046 \\ https://hal.science/hal-02592046}

Submitted on 15 May 2020

HAL is a multi-disciplinary open access archive for the deposit and dissemination of scientific research documents, whether they are published or not. The documents may come from teaching and research institutions in France or abroad, or from public or private research centers.
L'archive ouverte pluridisciplinaire HAL, est destinée au dépôt et à la diffusion de documents scientifiques de niveau recherche, publiés ou non, émanant des établissements d'enseignement et de recherche français ou étrangers, des laboratoires publics ou privés. 


\title{
Nonempirical Kinetic Modeling of Non-fickian Water Absorption Induced by a Chemical Reaction in Epoxy-Amine Networks
}

\author{
Xavier Colin
}

\begin{abstract}
In the last two decades, several studies made in our laboratory have shown that hydrolytic reactions may occur during water absorption and may be responsible for behavioral deviations from the classical Fick's law in epoxy-amine networks. On one hand, water is chemically consumed by specific groups initially present in the repetitive structural unit (e.g., unreacted epoxies and amides) or formed by oxidation under operating conditions. On the other hand, water establishes strong molecular interactions (hydrogen bonds) with new highly polar groups resulting from hydrolysis (alcohols and acids). Due to both contributions, the kinetic curves of water absorption no longer tend towards an equilibrium value, i.e., a final saturation plateau, but display a slow and continuous increase over time in the water mass uptake. On this basis, a diffusion/reaction model has been developed for predicting such a peculiar water sorption behavior. In addition, the classical Henry's law has been modified for describing the changes in boundary conditions during the course of the hydrolytic reaction. This chapter provides an overview of the recent theoretical advances made in this field and demonstrates, through two case studies, the good predictive value of the kinetic modeling approach set up in our laboratory.
\end{abstract}

Keywords Epoxy-amine networks • Water absorption - Hydrolysis • Fick's law deviation - Kinetic modeling

\section{Introduction}

Epoxy-amine networks are widely used in many industrial fields, such as aeronautics and space, automotive industry, nuclear energy, building and civil engineering, as matrices of fiber reinforced composite materials, structural adhesives of

\footnotetext{
X. Colin $(\bowtie)$

Laboratoire PIMM, Arts et Métiers ParisTech, 151 Boulevard de L’Hôpital, 75013 Paris, France

e-mail: xavier.colin@ensam.eu
} 
bonded assemblies, but also protective coatings, in particular paintings, varnishes and lacquers. Many studies have been conducted for tentatively elucidating their physical and chemical aging mechanisms and for evaluating their long-term durability under the combined effects of various environmental stresses such as temperature, UV and ionizing radiations, oxygen, water, etc. [1-3].

These polymers are known to be very sensitive to moisture. First of all, they can absorb large amounts of water due to the presence of highly polar groups (hydroxyls for example) in their repetitive structural unit, which establish strong molecular interactions (hydrogen bonds) with water molecules. That is the reason why they undergo an important external plasticization when they are initially in the glassy state. As an example, an ideal DGEBA-DDM network absorbs more than 2 wt $\%$ of water in $100 \% \mathrm{RH}$ at $25{ }^{\circ} \mathrm{C}$, which reduces its glass transition temperature $\mathrm{T}_{\mathrm{g}}$ by about $36^{\circ} \mathrm{C}[4]$.

In addition, epoxy-amine networks can undergo a hydrolysis reaction when they contain specific chemical groups known to be reactive with water. These latter can be initially present in the repetitive structural unit as, for instance, amides in networks based on amidoamine hardeners [5] or unreacted epoxies in non-ideal networks [6]. But, they may also be formed by a radical chain oxidation reaction activated by external factors (e.g., increase in temperature, UV or ionizing radiation, or chemical reagent acting as a radical initiator) under operating conditions. These chemical groups are then amides and esters resulting from the oxidation of aminoand oxy-methylenes respectively [7]. In both cases, hydrolysis will lead to the formation and accumulation of new hydroxyl groups (alcohols and acids) and consequently, to significant changes in water transport properties in epoxy-amine networks.

This chapter proposes to review all these physico-chemical mechanisms and to derive, from these latter, a general kinetic model capable of predicting two examples of behavioral deviations from the classical Fick's law reported in the literature for epoxy-amine networks.

\section{Water Absorption in the Absence of Hydrolysable Groups}

In the absence of hydrolysable groups in epoxy-amine networks, water absorption obeys the classical Fick's second law [6, 8, 9]. A typical kinetic curve of water absorption is plotted versus the square root of time in Fig. 1a. Two time domains can be clearly distinguished:

I. The transient regime during which the water mass uptake $\mathrm{m}$ (expressed in wt $\%$ ) increases linearly with the square root of time. The slope of this straight line allows the coefficient D of water diffusion to be determined. During this period, water is heterogeneously distributed in the sample thickness as schematized in Fig. 1b. 
(a) $\mathrm{m}$

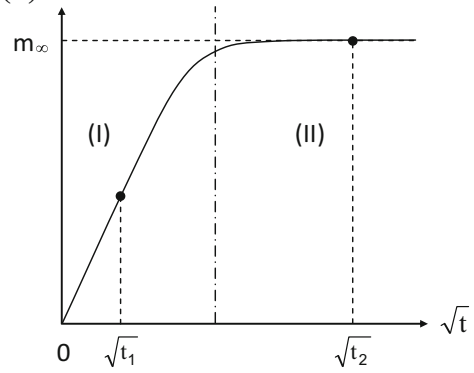

(b) $\mathrm{m}$

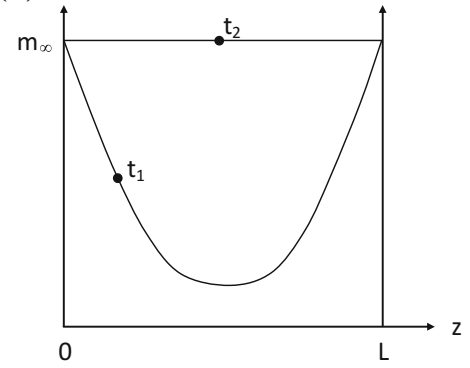

Fig. 1 a Typical kinetic curve of water absorption for a Fick's diffusion process. b Water gradient in the sample thickness at two different times of exposure

II. The final saturation plateau for which $\mathrm{m}$ has reached its maximum value $\mathrm{m}_{\infty}$ throughout the sample thickness (for the exposure conditions under study). Thenceforth, water is homogeneously distributed throughout the sample thickness.

The equilibrium mass uptake $\mathrm{m}_{\infty}$, mass fraction $\mu_{\infty}$ and concentration $\mathrm{C}_{\infty}$ of absorbed water in the polymer sample are linked by the following relationships:

$$
\mu_{\infty}=\frac{\mathrm{m}_{\infty}}{1+\mathrm{m}_{\infty}} \quad \text { and } \quad \mathrm{C}_{\infty}=\frac{\mathrm{m}_{\infty}}{18}\left(\text { expressed in } \mathrm{mol} \mathrm{g}^{-1}\right)
$$

\subsection{Equilibrium Properties}

Since water is far below its critical point $\left(\mathrm{T}_{C}=647 \mathrm{~K}\right)$, the pertinent environmental parameter is the water activity $a$. Let us remember that for humid atmospheres:

$$
\mathrm{a}=\frac{\mathrm{p}_{\mathrm{V}}}{\mathrm{p}_{\mathrm{VS}}}=\frac{\mathrm{RH}}{100}
$$

where $\mathrm{p}_{\mathrm{V}}$ and $\mathrm{p}_{\mathrm{VS}}$ are respectively the water partial pressure in the atmosphere and the saturated vapor pressure of water.

In the absence of hydrolysable groups in epoxy-amine networks, $\mathrm{C}_{\infty}$ varies linearly with a over the whole activity range (Fig. 2). In other words, $\mathrm{C}_{\infty}$ obeys the classical Henry's law [10]:

$$
\mathrm{C}_{\infty}=\mathrm{Ha}
$$

where $H$ is almost independent of temperature. 
Fig. 2 Typical sorption isotherm of Henry's type

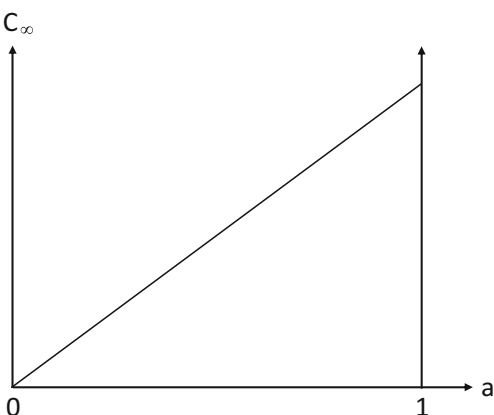

\subsection{Origin of Hydrophilicity}

In the 1980 s, many authors have tried to relate the polymer hydrophilicity to the available free volume [11-14], but such theory fails in explaining why free-volume-rich organic substances, such as liquid hydrocarbons and silicone rubbers, are hydrophobic. Today, it seems clear that hydrophilicity is essentially linked to the molecular interactions between water molecules and polar groups in the polymer matrix. In a first approach, $\mathrm{m}_{\infty}$ can be roughly estimated from Hildebrandt's solubility parameter $\delta$. Indeed this latter, which is directly related to the chemical structure of the polymer, gives access to polymer-solvent interactions. It can be written:

$$
\delta=\frac{\mathrm{F}}{\mathrm{V}}
$$

with $\mathrm{F}$ the molar attraction constant and $V$ the molar volume of the polymer.

According to Van Krevelen's theory [15], both quantities are molar additive functions, i.e., they can be calculated by summing the molar contributions of the different chemical groups composing the repetitive structural unit:

$$
\mathrm{F}=\sum \mathrm{F}_{\mathrm{i}} \quad \text { and } \quad \mathrm{V}=\sum \mathrm{V}_{\mathrm{i}}
$$

Table 1 summarizes the values of $\mathrm{F}_{i}$ and $\mathrm{V}_{i}$ proposed by Small [16], Van Krevelen [17], Hoy [18] and Fedors [19] for usual chemical groups.

The literature values of $\mathrm{m}_{\infty}$ in $100 \% \mathrm{RH}$ at $25^{\circ} \mathrm{C}$ of different polymers have been compiled and plotted versus $\delta$ (calculated from Eqs. 2.4 and 2.5) in the loglog diagram of Fig. 3.

A correlation is clearly observed between both quantities. It can be written:

$$
\mathrm{m}_{\infty}=7.1 \times 10^{-10} \delta^{6.86}
$$


Table 1 Molar contributions to F [16-18] and V [19] of usual chemical groups. Ph designates an aromatic ring

\begin{tabular}{|c|c|c|}
\hline Group & $\mathrm{F}_{\mathrm{i}}\left(\mathrm{J}^{1 / 2} \mathrm{~cm}^{3 / 2} \mathrm{~mol}^{-1}\right)$ & $\mathrm{V}_{\mathrm{i}}\left(\mathrm{cm}^{3} \mathrm{~mol}^{-1}\right)$ \\
\hline$-\mathrm{CH}_{3}$ & 370 & 33.5 \\
\hline$-\mathrm{CH}_{2-}$ & 275 & 16.1 \\
\hline$>\mathrm{CH}-$ & 115 & -1 \\
\hline$>\mathrm{C}<$ & 15 & -19.5 \\
\hline$-\mathrm{Ph}-$ & 1680 & 89.4 \\
\hline$-\mathrm{O}-$ & 200 & 3.8 \\
\hline$>\mathrm{N}_{-}$ & 125 & -9 \\
\hline$-\mathrm{NH}_{2}$ & 490 & 19.2 \\
\hline$-\mathrm{CO}-$ & 560 & 10.8 \\
\hline$-\mathrm{O}-\mathrm{CO}-$ & 590 & 18 \\
\hline -O-CO-O- & 760 & 22 \\
\hline - $\mathrm{CO}-\mathrm{O}-\mathrm{CO}-$ & 960 & 30 \\
\hline$-\mathrm{NH}-\mathrm{CO}-$ & 1110 & 9.5 \\
\hline$-\mathrm{CO}-\mathrm{OH}$ & 825 & 28.5 \\
\hline$-\mathrm{OH}$ & 610 & 10 \\
\hline$-\mathrm{SO}_{2-}$ & 845 & 19.6 \\
\hline
\end{tabular}

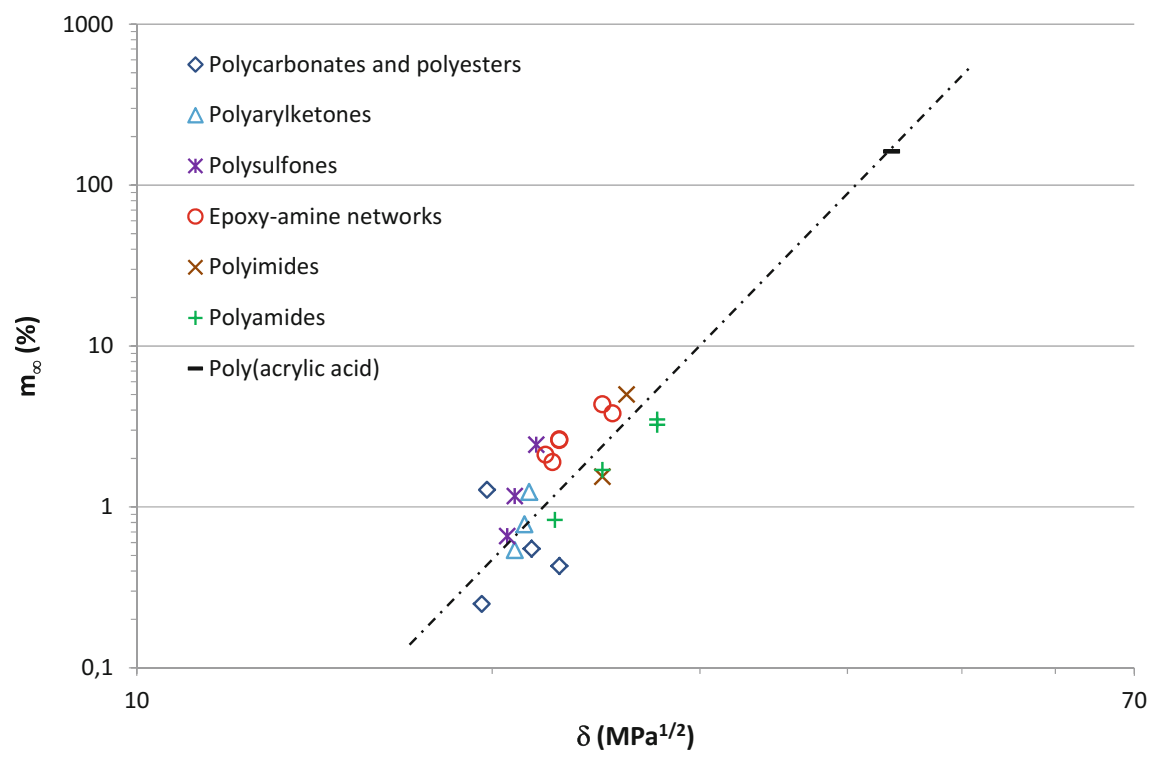

Fig. 3 Equilibrium water mass uptake (in $100 \% \mathrm{RH}$ at $25^{\circ} \mathrm{C}$ ) versus solubility parameter for 24 polymers 
Epoxy-amine networks are moderately polar polymers $\left(22<\delta<25 \mathrm{MPa}^{1 / 2}\right)$. They absorb typically between 1 and 4 wt $\%$ of water in $100 \% \mathrm{RH}$ at $25{ }^{\circ} \mathrm{C}$.

\subsection{Effect of Structure on Hydrophilicity}

According to Van Krevelen [15], $\mathrm{C}_{\infty}$ would be a molar additive function, i.e., each chemical group of the repetitive structural unit would be characterized by a molar contribution to hydrophilicity $\mathrm{H}_{i}$ (in mole of water per mole of group) independent of its chemical neighbors:

$$
\mathrm{C}_{\infty}=\left(\frac{18}{\mathrm{M}_{\mathrm{RSU}}} \sum \mathrm{H}_{\mathrm{i}}\right) \times \frac{\mathrm{HR}}{100},
$$

where $\mathrm{M}_{\mathrm{RSU}}$ is the molar mass of the repetitive structural unit. Table 2 summarizes the values of $\mathrm{H}_{i}$ determined by Barrie [20] for usual chemical groups in $100 \% \mathrm{RH}$ at $25{ }^{\circ} \mathrm{C}$. On this basis, three main categories of chemical groups can be defined:

- Apolar groups, such as aromatic and aliphatic hydrocarbon structures, which have a negligible contribution to hydrophilicity: $\mathrm{H}_{\mathrm{i}} \approx 0 \mathrm{~mol} / \mathrm{mol}$;

- Moderately polar groups, for instance ethers, ketones and esters, which have a relatively low contribution to hydrophilicity: $\mathrm{H}_{i}=0.1-0.3 \mathrm{~mol} / \mathrm{mol}$;

- And highly polar groups, for instance acids, amides, and alcohols, which establish intense molecular interactions with water molecules (hydrogen bonds) and absorb typically $\mathrm{H}_{i}=1-2 \mathrm{~mol} / \mathrm{mol}$.

Equation 2.7 can be used for estimating the orders of magnitude of $\mathrm{C}_{\infty}$ for the main polymer families. In contrast, this approach fails in predicting the hydrophilicity variations within a same polymer family which displays large concentration differences in polar groups, such as epoxy-amine networks [6] and polysulfones [21]. Indeed in these two latter, it has been found that $\mathrm{C}_{\infty}$ does not

Table 2 Molar contributions to hydrophilicity (in moles of water per mole of group) of usual chemical groups in $100 \% \mathrm{RH}$ at $25{ }^{\circ} \mathrm{C}[20] . \mathrm{Ph}$ designates an aromatic ring

\begin{tabular}{l|l|l}
\hline Polarity & Group & $\mathrm{H}_{\mathrm{i}}(\mathrm{mol} / \mathrm{mol})$ \\
\hline-- & $-\mathrm{CH}_{3}$ & 0.00005 \\
\cline { 2 - 2 } & $-\mathrm{CH}_{2}-$ & \\
\cline { 2 - 3 } & $>\mathrm{CH}-$ & \\
\cline { 2 - 3 } & $-\mathrm{Ph}-$ & 0.1 \\
\hline+ & $-\mathrm{O}-$ & 0.2 \\
\cline { 2 - 3 } & $-\mathrm{CO}-$ & 0.3 \\
\cline { 2 - 3 } & $-\mathrm{O}-\mathrm{CO}-$ & 1.3 \\
\hline \multirow{4}{*}{++} & $-\mathrm{CO}-\mathrm{OH}$ & 2 \\
\hline & $-\mathrm{CO}-\mathrm{NH}-$ & 2 \\
\cline { 2 - 3 } & $-\mathrm{OH}$ & \\
\hline
\end{tabular}


increase linearly but exponentially with the concentration of polar groups (i.e., hydroxyls and sulfones, respectively).

Gaudichet-Maurin et al. [21] have proposed a theory for tentatively explaining such a behavior. According to these authors, an hydrophilic site would not be a single but a pair of polar groups having to satisfy some geometric requirements (in particular an optimal distance between them) in order to establish a double hydrogen bond with a water molecule. As schematized in Fig. 4, the probability of finding two polar groups at this optimal distance would increase exponentially with their concentration, which could effectively explain the mathematical shape observed experimentally for the curve: $\mathrm{C}_{\infty}=\mathrm{f}$ ([Polar group $]$ ).

More recently, Courvoisier [22] has compiled the literature values of $\mathrm{C}_{\infty}$ in $100 \% \mathrm{RH}$ at $25^{\circ} \mathrm{C}$ of different polymers and plotted them versus the concentration of the most polar group in the repetitive structural unit (Fig. 5). It can be seen that all the points are placed around only three master curves, which allows to distinguish three main categories of polar groups: slightly (esters and carbonates), moderately (aryl ketones, amides and imides), and highly polar groups (hydroxyls and sulfones). Thus, it appears clearly that all carbonyl groups do not display the same behavior. The lower contribution to hydrophilicity of esters and carbonates had been already reported in the literature by several other authors, for instance in reference [23].

Since these three curves display an exponential shape, it can be assumed that the previous theory can be generalized to all polymers. A general semi-empirical structure/ $\mathrm{C}_{\infty}$ relationship can be proposed:

$$
\mathrm{C}_{\infty}=\mathrm{A} \operatorname{Exp}\{\mathrm{B}[\text { Polar group }]\} \times \frac{\mathrm{HR}}{100},
$$

where $A$ is almost independent of the chemical structure: $A=(1.23 \pm 0.41) 10^{-1}$ mol. $\mathrm{L}^{-1}$ for all polymers. In contrast, $B$ is an increasing function of the group polarity.

In fact, $B$ is found to be proportional to the "elemental" solubility parameter of the polar group under consideration:

$$
\mathrm{B}=(6.7 \pm 1.0) 10^{-3} \times \delta
$$

Fig. 4 Schematization of the probability increase of finding two polar groups at an optimal distance for establishing a double hydrogen bond with a water molecule o: polar group. $\wedge$ : water molecule
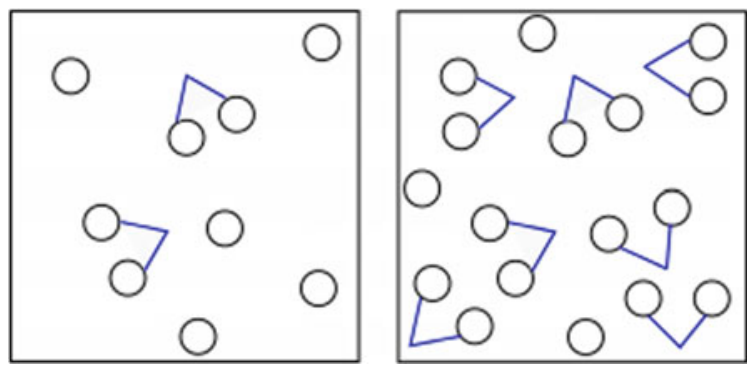


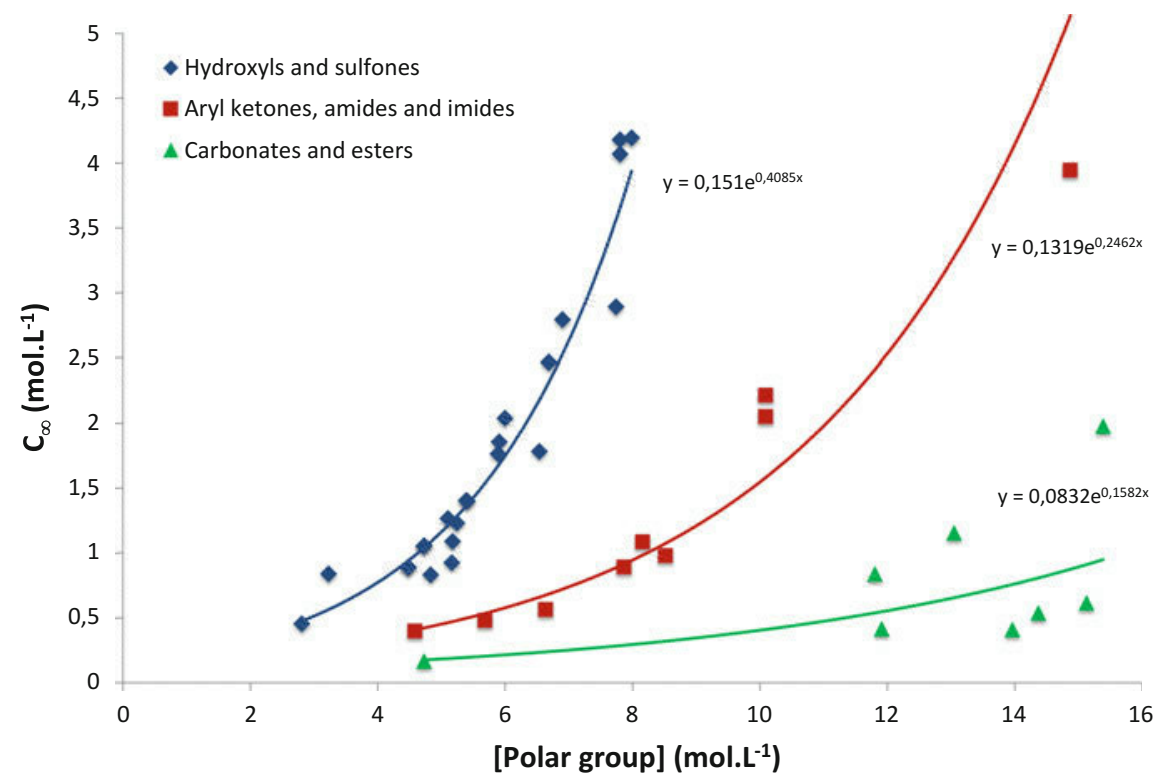

Fig. 5 Equilibrium water concentration (in $100 \% \mathrm{RH}$ at $25^{\circ} \mathrm{C}$ ) versus polar group concentration for 40 polymers

Table 3 Solubility parameters of common chemical groups. $\mathrm{Ph}$ designates an aromatic ring

\begin{tabular}{|c|c|c|}
\hline Polarity & Group & $\delta\left(\mathrm{MPa}^{1 / 2}\right)$ \\
\hline \multirow[t]{4}{*}{--} & $-\mathrm{CH}_{3}$ & \multirow[t]{4}{*}{$16.8 \pm 2.1$} \\
\hline & $-\mathrm{CH}_{2-}$ & \\
\hline & $>\mathrm{CH}-$ & \\
\hline & $-\mathrm{Ph}-$ & \\
\hline \multirow[t]{3}{*}{+} & $-\mathrm{O}_{-}$ & 22.8 \\
\hline & $-\mathrm{O}-\mathrm{CO}-$ & \multirow[t]{2}{*}{$27.4 \pm 0.1$} \\
\hline & $-\mathrm{CO}-\mathrm{O}-\mathrm{CO}-$ & \\
\hline \multirow[t]{4}{*}{++} & $-\mathrm{CO}-$ & \multirow[t]{4}{*}{$32.6 \pm 2.3$} \\
\hline & $-\mathrm{CO}-\mathrm{H}$ & \\
\hline & $-\mathrm{CO}-\mathrm{NH}_{2}$ & \\
\hline & -CO-NH- & \\
\hline \multirow[t]{2}{*}{+++} & $-\mathrm{SO}_{2}$ & \multirow[t]{2}{*}{$50.4 \pm 2.5$} \\
\hline & $-\mathrm{OH}$ & \\
\hline
\end{tabular}

Table 3 summarizes the values of $\delta$ calculated for usual chemical groups from the values of cohesive energy $\mathrm{E}_{\mathrm{coh}}$ and molar volume $V$, reported respectively by Fedors [19] and Hoy [18], and applying the well-known relationship: 


$$
\delta=\left(\frac{\mathrm{E}_{\mathrm{coh}}}{\mathrm{V}}\right)^{1 / 2}
$$

\subsection{Effect of Structure on Diffusivity}

In contrast, the relationships between polymer structure and water diffusivity are far from being totally elucidated. Thominette et al. [24] have observed that $D$ is a decreasing function of hydrophilicity in different polymer families, for instance in epoxy-amine networks, aromatic polysulfones, and polyester-styrene networks, but also in a series of polyethylenes differing by their initial concentration of oxygenated groups (pre-oxidation). This dependence shows that the diffusion rate is slowed down by the molecular interactions between water molecules and polar groups in the polymer matrix. A three-step scheme has been proposed [6] to describe such a diffusion mechanism (Fig. 6). According to this scheme, water diffusion is not highly influenced by the macromolecular mobility if the dissociation of the water-polymer complex (I) is slower than the water migration between neighboring hydrophilic sites (II).

Courvoisier [22] has compiled the literature values of water permeability $P$ in $100 \% \mathrm{RH}$ at $25^{\circ} \mathrm{C}$ of different polymers and plotted them versus the concentration of the most polar group in the repetitive structural unit (Fig. 7). It can be seen that $P$ is of the same order of magnitude for all polymers. The data scattering within a same polymer family can be explained by the small effect on $P$ of secondary structural factors at higher scales, e.g., differences in crosslinking density in networks, differences in crystallinity ratio and crystalline lamellae thickness in semi-crystalline polymers, etc., which modify the tortuosity of the water diffusion path. In a first approximation, it can be written:

$$
\mathrm{P}=\mathrm{C}_{\infty} \times \mathrm{D}=10^{-9.7 \pm 0.7} \quad\left(\text { expressed in } \mathrm{mol} \mathrm{m}^{-1} \mathrm{~s}^{-1}\right)
$$

In other words, $D$ is inversely proportional to $\mathrm{C}_{\infty}$.

$$
\begin{array}{ll}
{\left[\mathrm{S}_{1} \ldots \mathrm{H}_{2} \mathrm{O}\right] \rightarrow \mathrm{S}_{1}+\mathrm{H}_{2} \mathrm{O}} & \text { (I) } \\
\mathrm{H}_{2} \mathrm{O} \rightarrow \text { migration until } \mathrm{S}_{2} & \text { (II) } \\
\mathrm{S}_{2}+\mathrm{H}_{2} \mathrm{O} \rightarrow\left[\mathrm{S}_{2} \ldots \mathrm{H}_{2} \mathrm{O}\right] & \text { (III) }
\end{array}
$$

Fig. 6 Three-step mechanism for water diffusion into polymer matrices [6]. $S_{1}$ and $S_{2}$ designate two neighboring hydrophilic sites and $\left[\mathrm{S}_{\mathrm{i}} \ldots \mathrm{H}_{2} \mathrm{O}\right]$ a hydrogen bonded water-polymer complex 


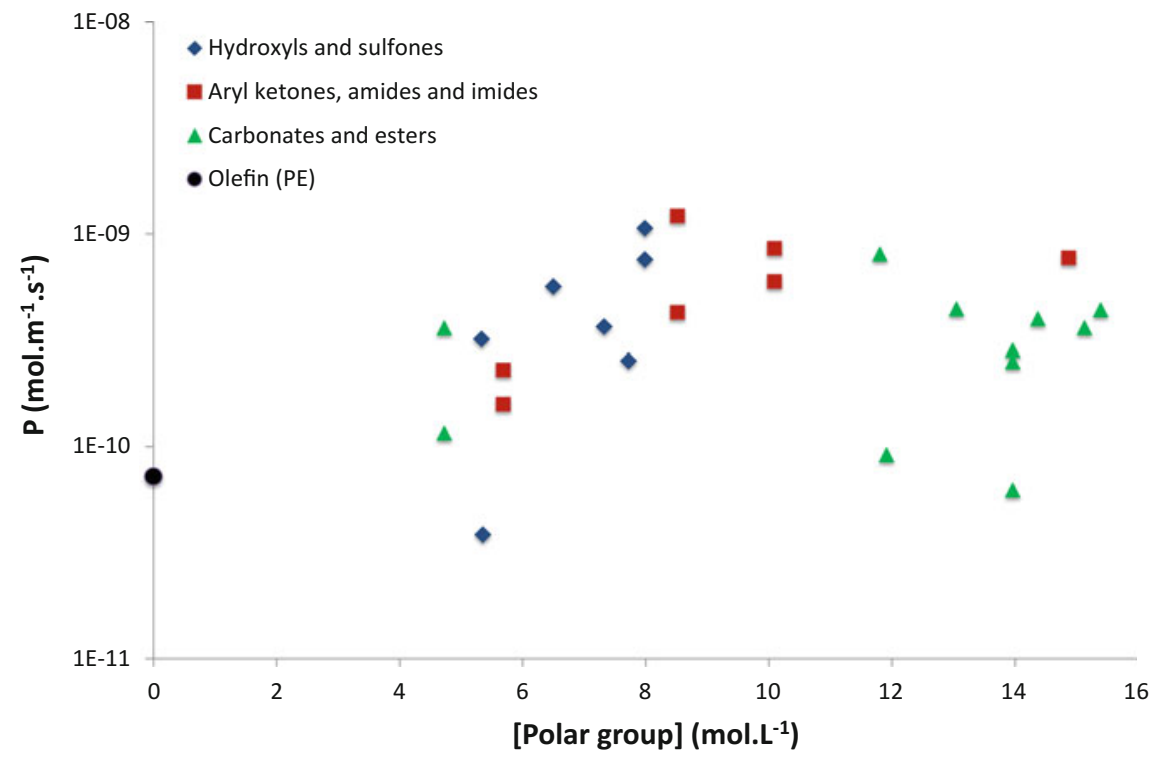

Fig. 7 Water permeability (in $100 \% \mathrm{RH}$ at $25{ }^{\circ} \mathrm{C}$ ) versus polar group concentration for 27 polymers

Fig. 8 Typical kinetic curves of water absorption for a

Langmuir's diffusion process

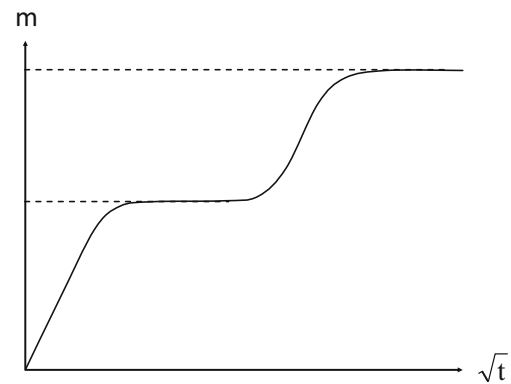

\section{Water Absorption in the Presence of Hydrolysable Groups}

In the presence of hydrolysable groups in epoxy-amine networks, different behavioral deviations from the classical Fick's law have been reported in the literature. Some of them are clearly related to chemical modifications.

In the case of non-ideal networks containing unreacted epoxy groups, water absorption displays a two-step behavior (Fig. 8) often classified in the categories of 
(a)<smiles>CC1CO1</smiles>

(b)

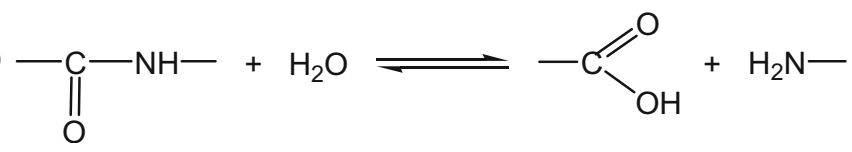

Fig. 9 Hydrolysis of epoxy (a) and amide groups (b). The double arrows indicate that the reaction is reversible, i.e. equilibrated by the reverse reaction of condensation

Langmuir processes $[25,26]$. In this case, water diffusion coexists with a water trapping-untrapping mechanism on particular sites. In fact, this mechanism is simply the reversible hydrolysis of unreacted epoxies [6] as schematized in Fig. 9a. During the second absorption stage characterizing the Langmuir process, the conversion of epoxies into much more polar groups (diols) consumes water molecules, but also increases significantly the polymer hydrophilicity. Of course, both additional contributions have to be considered in any approach of nonempirical kinetic modeling.

More recently, the same type of behavioral deviation has been reported for an ideal epoxy-amidoamine network [27]. However, in contrast to unreacted epoxies, amide groups are not located at dangling chain extremities, but within elastically active chains. As a result, their hydrolysis (Fig. 9b) leads also to a chain scission and, when two hydrolysis events take place on the same elastically active chain (i.e., at high conversion ratios), to the liberation of short macromolecular fragments (diacids) from the epoxy network. The superimposition of the resulting mass loss to the water mass uptake generates a complex sorption behavior [27]. Such behavior was already shown for aliphatic polyamides, in particular for PA 11 [28].

Let us note that hydrolysable groups are not necessarily initially present in epoxy-amine networks. Indeed, it cannot be excluded that they are formed and accumulated by a radical chain oxidation reaction activated by external factors (e.g., increase in temperature, UV or ionizing radiation, or chemical reagent acting as a radical initiator) under operating conditions. In that case, they may be esters and amides resulting from the oxidation of oxy- and amino-methylenes, respectively [7].

\section{Proposal of Kinetic Model}

On this basis, a general diffusion/reaction model has been developed for tentatively predicting the resulting kinetic curves of water absorption in epoxy-amine networks. Schematically, the water gradient in the thickness $L$ of a semi-infinite plate is 
calculated from a balanced equation, expressing that the change over time $t$ in water concentration $C$ in an elementary sublayer located at the depth $z$ beneath the sample surface is the difference between the water supply by diffusion (according to the Fick's second law) and the water consumption by the chemical reaction:

$$
\frac{\partial \mathrm{C}}{\partial \mathrm{t}}=\mathrm{D} \frac{\partial^{2} \mathrm{C}}{\partial \mathrm{z}^{2}}-\mathrm{r}(\mathrm{C})
$$

The mathematical expression of the water consumption rate is deduced from a kinetic analysis of the reversible hydrolysis scheme:

$$
\begin{aligned}
& \mathrm{E}+\mathrm{W} \rightarrow \mathrm{A}_{1}+\mathrm{A}_{2} \quad\left(\mathrm{k}_{\mathrm{h}}\right) \\
& \mathrm{A}_{1}+\mathrm{A}_{2} \rightarrow \mathrm{E}+\mathrm{W} \quad\left(\mathrm{k}_{\mathrm{c}}\right)
\end{aligned}
$$

where $E, W, A_{1}$, and $A_{2}$ account respectively for hydrolysable groups, water, and hydrolysis products. $\mathrm{k}_{h}$ and $\mathrm{k}_{c}$ are the respective rate constants of the hydrolysis and condensation reactions. The water consumption rate can be written as:

$$
\mathrm{r}(\mathrm{C})=-\frac{\mathrm{dC}}{\mathrm{dt}}=\mathrm{k}_{\mathrm{h}}[\mathrm{E}] \mathrm{C}-\mathrm{k}_{\mathrm{c}}\left[\mathrm{A}_{1}\right]\left[\mathrm{A}_{2}\right]
$$

The corresponding gradients in the sample thickness of hydrolysable groups and hydrolysis products are determined from complementary equations:

$$
\begin{gathered}
\frac{\mathrm{d}[\mathrm{E}]}{\mathrm{dt}}=-\mathrm{k}_{\mathrm{h}}[\mathrm{E}] \mathrm{C}+\mathrm{k}_{\mathrm{c}}\left[\mathrm{A}_{1}\right]\left[\mathrm{A}_{2}\right] \\
\frac{\mathrm{d}\left[\mathrm{A}_{1}\right]}{\mathrm{dt}}=\frac{\mathrm{d}\left[\mathrm{A}_{2}\right]}{\mathrm{dt}}=\mathrm{k}_{\mathrm{h}}[\mathrm{E}] \mathrm{C}-\mathrm{k}_{\mathrm{c}}\left[\mathrm{A}_{1}\right]\left[\mathrm{A}_{2}\right]
\end{gathered}
$$

The system of Eqs. 4.1-4.4 has been solved simultaneously in space (z) and time $(t)$ using the numerical algorithms recommended for problems of chemical kinetics in the literature. Let us note that these algorithms are already implemented in the commercial MATLAB ${ }^{\circledR}$ software under the names of ODE23 s and ODE23 tb. The initial (throughout the sample thickness) and boundary conditions (at the sample surface) used for this resolution are recalled below:

- At $\mathrm{t}=0$ and any $\mathrm{z}: \mathrm{C}(\mathrm{z}, 0)=0,[\mathrm{E}](\mathrm{z}, 0)=[\mathrm{E}]_{0}$ and $\left[\mathrm{A}_{1}\right](\mathrm{z}, 0)=\left[\mathrm{A}_{2}\right](\mathrm{z}, 0)=0$.

- When $\mathrm{t}>0$, at $\mathrm{z}=0$ and $\mathrm{L}: \mathrm{C}(0, \mathrm{t})=\mathrm{C}(\mathrm{L}, \mathrm{t})=\mathrm{C}_{\mathrm{S}}(\mathrm{t})$.

Let us remember that, due to the hydrolysis reaction, the water concentration $\mathrm{C}_{S}$ at the sample surface is no longer a constant but it is an increasing function of time. It can be determined from Eq. 2.8 if the total concentration of highly polar groups (i.e., hydroxyls) at any time $\mathrm{t}$ is known. The initial value of $\mathrm{C}_{S}$ corresponds to the equilibrium water concentration $\mathrm{C}_{\infty}$ that should be found if the epoxy-amine network under consideration did not contain hydrolysable groups. The increase in $\mathrm{C}_{S}$ against time of exposure can be determined by introducing the solution of Eq. 4.4 
into Eq. 2.8. Indeed, for the two hydrolysis examples reported in Fig. 9, this latter writes:

$$
\mathrm{C}_{\mathrm{S}}=\mathrm{A} \operatorname{Exp}\{\mathrm{B}[\mathrm{OH}]\}
$$

with $A=1.51 \times 10^{-1} \mathrm{~mol} \mathrm{~L}{ }^{-1}$ and $B=4.09 \times 10^{-1} \mathrm{~L} \mathrm{~mol}^{-1}$. If considering the definition of $\mathrm{C}_{\infty}$, this equation can be rewritten:

$$
\mathrm{C}_{\mathrm{S}}=\mathrm{C}_{\infty} \operatorname{Exp}\left\{\mathrm{B}\left([\mathrm{OH}]-[\mathrm{OH}]_{0}\right)\right\}
$$

Since hydroxyl groups $(\mathrm{OH})$ come from alcohols (Al) and acids (Ac), it comes finally:

$$
\mathrm{C}_{\mathrm{S}}=\mathrm{C}_{\infty} \operatorname{Exp}\left\{\mathrm{B}\left([\mathrm{Al}]-[\mathrm{Al}]_{0}\right)\right\} \times \operatorname{Exp}\left\{\mathrm{B}\left([\mathrm{Ac}]-[\mathrm{Ac}]_{0}\right)\right\}
$$

In addition, always due to the hydrolysis reaction, the coefficient of water diffusion $D$ through the sample thickness is no longer a constant but a decreasing function of time. It can be determined from Eq. 2.11 through replacing $\mathrm{C}_{\infty}$ by $\mathrm{C}_{S}$. The initial value of $D$ corresponds to the coefficient of water diffusion $\mathrm{D}_{0}$ that should be found if the epoxy-amine network under consideration did not contain hydrolysable groups. Since the water permeability is independent of the concentration of polar groups (Eq. 2.11), it can be written:

$$
\mathrm{C}_{\infty} \times \mathrm{D}_{0}=\mathrm{C}_{\mathrm{S}} \times \mathrm{D}
$$

If considering Eq. 4.7, it comes finally:

$$
\mathrm{D}=\frac{\mathrm{D}_{0}}{\operatorname{Exp}\left\{\mathrm{B}\left([\mathrm{Al}]-[\mathrm{Al}]_{0}\right)\right\} \times \operatorname{Exp}\left\{\mathrm{B}\left([\mathrm{Ac}]-[\mathrm{Ac}]_{0}\right)\right\}}
$$

As said before, the local value of the water mass uptake at the depth $z$ beneath the sample surface is the sum of two contributions: water diffusion and water consumption:

$$
\operatorname{dm}(\mathrm{z}, \mathrm{t})=\frac{18}{\rho}\left(\mathrm{C}+\int_{0}^{\mathrm{t}} \mathrm{r}(\mathrm{C}) \mathrm{dt}\right) \quad(\text { expressed in } \%)
$$

where $\rho$ is the initial polymer density. The global value of the water mass uptake is simply deduced by summing the local values of dm throughout the thickness $L$ of the semi-infinite plate:

$$
\mathrm{m}(\mathrm{t})=\frac{1}{\mathrm{~L}} \int_{0}^{\mathrm{L}} \mathrm{dm}(\mathrm{z}, \mathrm{t}) \mathrm{dz} \quad(\text { expressed in } \%)
$$




\section{Application to Two Case Studies}

The validity of the kinetic model described in the previous paragraph has been checked for the two hydrolysis examples reported in Fig. 9. Experimental data have been recovered from two distinct research studies [6, 27].

In the case of non-ideal networks containing unreacted epoxy groups, hydrolysis products are diols, therefore $\left[\mathrm{A}_{1}\right]=\left[\mathrm{A}_{2}\right]=[\mathrm{Al}]$ and $[\mathrm{Ac}]=[\mathrm{Ac}]_{0}=0$. As an example, the simulations of the kinetic curves of water absorption in $100 \% \mathrm{RH}$ at $50{ }^{\circ} \mathrm{C}$ of DGEBD-ETHA networks only differing by their initial concentrations of unreacted epoxy groups are reported in Fig. 10. These networks were synthetized from DGEBD/ETHA mixtures with different $r=$ amine/epoxy functional ratios [6].

A satisfactory agreement can be observed between theory and experiment. The values of the rate constants $\mathrm{k}_{h}$ and $\mathrm{k}_{c}$ and the coefficient of water diffusion $\mathrm{D}_{0}$ used for these simulations are specified in Table 4.

On one hand, it is checked that the rate constants take almost the same values in all simulations. At $50^{\circ} \mathrm{C}$, their average values are:

$$
\mathrm{k}_{\mathrm{h}}=3.4 \times 10^{-8} \mathrm{~L} \mathrm{~mol}^{-1} \mathrm{~s}^{-1} \quad \text { and } \quad \mathrm{k}_{\mathrm{c}}=1.5 \times 10^{-8} \mathrm{Lmol}^{-1} \mathrm{~s}^{-1}
$$

Thus, it is found that: $\mathrm{k}_{h} \approx 2 \times \mathrm{k}_{c}$. In other words, hydrolysis of epoxy groups is favored over diols condensation for long periods of exposure.

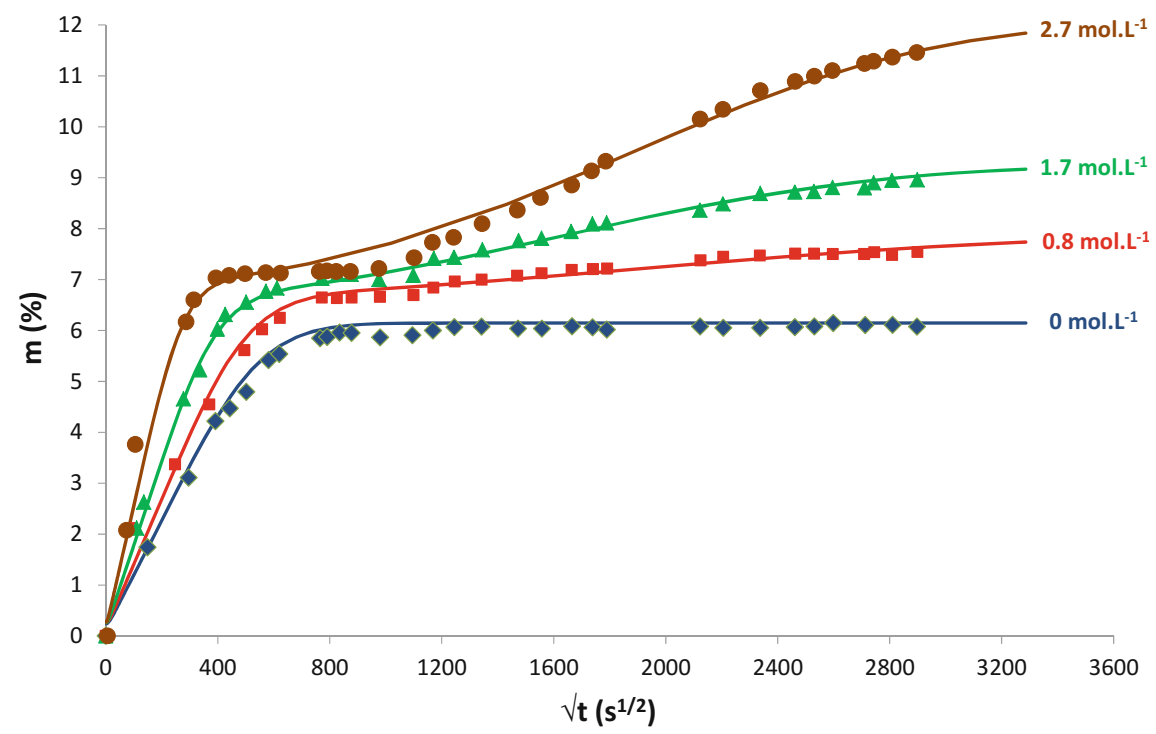

Fig. 10 Kinetic curves of water absorption in $100 \%$ RH at $50{ }^{\circ} \mathrm{C}$ of non-ideal DGEBD-ETHA networks. Comparison between theory (solid curves) and experiments (symbols). The concentrations of unreacted epoxies are mentioned next to the curves 
Table 4 Rate constants and coefficient of water diffusion used for simulating the kinetic curves of Fig. 10

\begin{tabular}{l|l|l|l}
\hline$[E]_{0}\left(\mathrm{~mol} \mathrm{~L}^{-1}\right)$ & $\mathrm{k}_{\mathrm{h}}\left({\left.\mathrm{L} . \mathrm{mol}^{-1} \mathrm{~s}^{-1}\right)}\right.$ & $\mathrm{k}_{\mathrm{c}}\left(\mathrm{L} \mathrm{mol}^{-1} \mathrm{~s}^{-1}\right)$ & $\mathrm{D}_{0}\left(\mathrm{~m}^{2} \mathrm{~s}^{-1}\right)$ \\
\hline 0.0 & - & - & $2.5 \times 10^{-12}$ \\
\hline 0.8 & $3.0 \times 10^{-8}$ & $1.9 \times 10^{-8}$ & $3.0 \times 10^{-12}$ \\
\hline 1.7 & $3.8 \times 10^{-8}$ & $1.1 \times 10^{-8}$ & $5.0 \times 10^{-12}$ \\
\hline 2.7 & $3.3 \times 10^{-8}$ & $1.5 \times 10^{-8}$ & $1.0 \times 10^{-11}$ \\
\hline
\end{tabular}

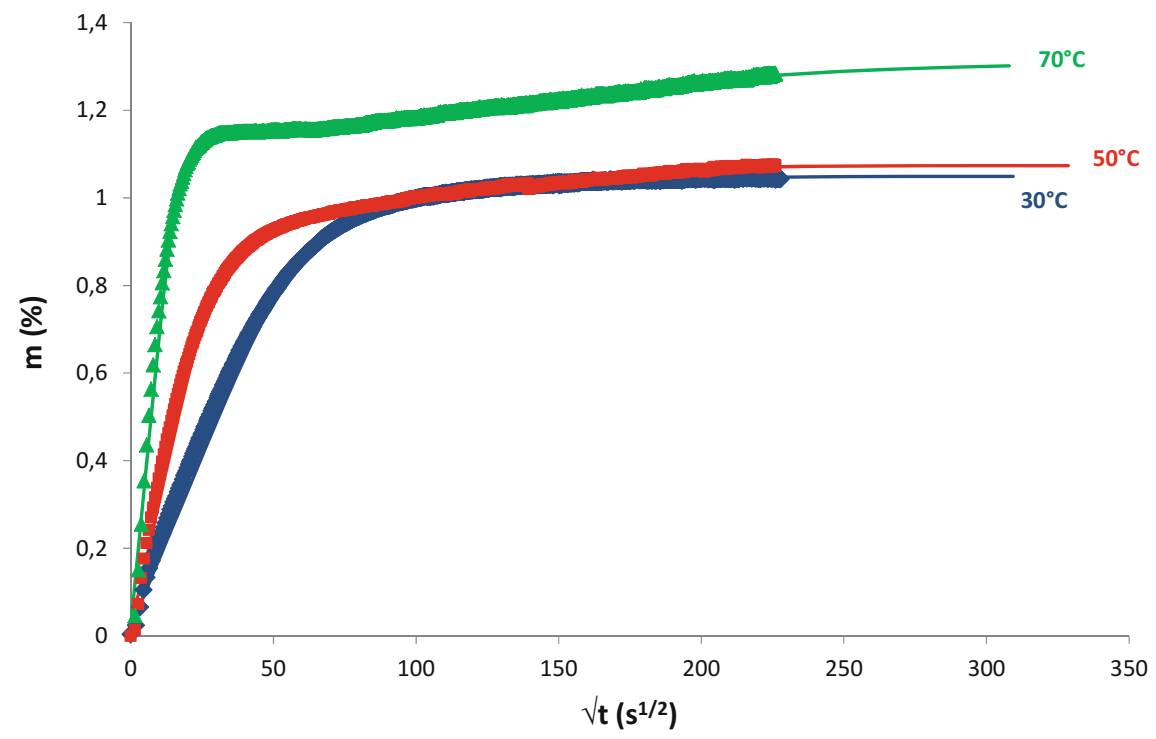

Fig. 11 Kinetic curves of water absorption in 50\% RH at 30,50 and $70{ }^{\circ} \mathrm{C}$ of an ideal DGEBA-PAA network. Comparison between theory (solid curves) and experiments (symbols). The temperatures of exposure are mentioned next to the curves

On the other hand, as expected, the coefficient of water diffusion is a decreasing function of the network polarity. Indeed, $D_{0}$ is equal to $2.5 \times 10^{-12} \mathrm{~m}^{2} \mathrm{~s}^{-1}$ for the ideal network with an initial concentration of hydroxyl groups of $[\mathrm{OH}]_{0}=$ $8.0 \mathrm{~mol} \mathrm{~L}-1$, whereas it increases up to $1.0 \times 10^{-11} \mathrm{~m}^{2} \mathrm{~s}^{-1}$ for the least ideal network having an initial concentration of hydroxyl groups of $[\mathrm{OH}]_{0}=6.2 \mathrm{~mol} \mathrm{~L}^{-1}$.

In the case of ideal networks containing amide groups, hydrolysis products are acids and amines, therefore $\left[\mathrm{A}_{1}\right]=[\mathrm{Ac}],\left[\mathrm{A}_{2}\right]=[\mathrm{Am}]$, and $[\mathrm{Al}]=[\mathrm{Al}]_{0}$. As an example, the simulations of the kinetic curves of water absorption in $50 \% \mathrm{RH}$ at 30 , 50 , and $70{ }^{\circ} \mathrm{C}$ of a DGEBA-PAA network are reported in Fig. 11. PAA is a complex amidoamine hardener resulting from the condensation of fatty acids with polyamines (mostly triethylenetetramine) [27]. 
Table 5 Rate constants and coefficient of water diffusion used for simulating the kinetic curves of Fig. 11

\begin{tabular}{l|l|l|l}
\hline $\mathrm{T}\left({ }^{\circ} \mathrm{C}\right)$ & $\mathrm{k}_{\mathrm{h}}\left(\mathrm{L} \mathrm{mol}^{-1} \mathrm{~s}^{-1}\right)$ & $\mathrm{k}_{\mathrm{c}}\left(\mathrm{L} \mathrm{mol}^{-1} \mathrm{~s}^{-1}\right)$ & $\mathrm{D}_{0}\left(\mathrm{~m}^{2} \mathrm{~s}^{-1}\right)$ \\
\hline 30 & $6.5 \times 10^{-6}$ & $1.7 \times 10^{-4}$ & $5.0 \times 10^{-13}$ \\
\hline 50 & $9.5 \times 10^{-6}$ & $1.5 \times 10^{-4}$ & $2.0 \times 10^{-12}$ \\
\hline 70 & $9.5 \times 10^{-6}$ & $1.0 \times 10^{-4}$ & $6.0 \times 10^{-12}$ \\
\hline
\end{tabular}

Here also, a satisfactory agreement can be observed between theory and experiment. The values of the rate constants $\mathrm{k}_{h}$ and $\mathrm{k}_{c}$ and the diffusion coefficient $\mathrm{D}_{0}$ used for these simulations are specified in Table 5.

On one hand, it can be seen that the rate constants are almost independent of temperature. In fact, $\mathrm{k}_{c}$ displays the same order of magnitude as in aliphatic polyamides, e.g., in PA66 [29]. In contrast, $\mathrm{k}_{h}$ is about two decades higher in the epoxy-amidoamine network under consideration than in PA 66. Unfortunately, structure/rate constants relationships are not well known yet in this domain. It is thus too premature to give an explanation.

On the other hand, the values of the coefficient of water diffusion are in very good agreement with those usually reported in the literature for ideal epoxy-amine networks [30]. It is found that $\mathrm{D}_{0}$ obeys an Arrhenius law with a pre-exponential factor of $1.5 \times 10^{-3} \mathrm{~m}^{2} \mathrm{~s}^{-1}$ and an activation energy of $54.9 \mathrm{~kJ} \mathrm{~mol}^{-1}$.

\section{Conclusions}

A nonempirical kinetic model has been elaborated for predicting the non-Fickian water absorption induced by a reversible hydrolysis reaction in epoxy-amine networks. This model couples water diffusion and its consumption by the chemical reaction in a system of three differential equations, and takes into account the changes in network hydrophilicity due to the formation of new highly polar groups (alcohols and acids). Its validity has been successfully checked from the experimental results of two case studies conducted in the last two decades in our laboratory.

This model gives access to kinetic parameters (rate constants of hydrolysis and condensation, and coefficient of water diffusion) that are hardly accessible experimentally. The values found for the coefficient of water diffusion are in very good agreement with those already reported in the literature for ideal epoxy-amine networks. In contrast, the values obtained for the rate constants are still questionable. No doubt, these latter have to be the object of a specific study devoted to the humid aging of a large series of epoxy-amine networks containing a well-known concentration of hydrolysable groups after synthesis, but also after storage at room temperature (in particular, in a completely dry atmosphere). 


\section{References}

1. Colin X, Verdu J (2011) Thermooxidative and thermohydrolytic aging of organic composite matrices. In: Song DB (ed) Resin composites: properties, production and applications, Chap 7. Nova Science Publishers, New York, pp 255-298

2. Colin X, Verdu J (2012) Aging of organic matrix composite materials. In: Nicolais L, Borzacchiello A, Lee Song SM (eds) Wiley Encyclopedia of composites, 2nd edn, Chap 4. Wiley, New York, pp 35-49

3. Colin X, Verdu J (2014) Humid ageing of organic matrix composites. In: Davies P, Rajapakse YDS (eds) Solid mechanics and its applications 208: durability of composites in a marine environment, Chap 3. Springer, Dordrecht, pp 47-114

4. Bellenger V, Verdu J, Morel E (1989) Structure-properties relationships for densely crosslinked epoxy-amine systems based on epoxide or amine mixtures. Part 2: Water absorption and diffusion. J Mater Sci 24:63-68

5. Abdelkader AF, White JR (2005) Water absorption in epoxy resins: The effects of the crosslinking agent and curing temperature. J Appl Polym Sci 98(6):2544-2549

6. Tcharkhtchi A, Bronnec Y, Verdu J (2000) Water absorption characteristics of diglycidylether of butane diol-3,5-diethyl-2,4-diaminotoluene networks. Polymer 41(15):5777-5785

7. Colin X, Fayolle B, Cinquin J (2016) Further progress in the kinetic modelling of the thermal oxidation of epoxy-diamine matrices. Mater Tech 104(2):202

8. Li L, Yu Y, Wu Q, Zhan G, Li S (2009) Effect of chemical structure on water sorption of amine-cured epoxy resins. Corros Sci 51:3000-3006

9. Perrin FX, Nguyen MH, Vernet JL (2009) Water transport in epoxy-aliphatic amine networks. Influence of curing cycles. Eur Polym J 45:1524-1534

10. Merdas I, Thominette F, Tcharkhtchi A, Verdu J (2002) Factors governing water absorption by composite matrices. Compos Sci Technol 62:487-492

11. Adamson MJ (1980) Thermal expansion and swelling of cured epoxy resin used in graphite/epoxy composite materials. J Mater Sci 15:1736-1745

12. Enns JB, Gilham JK (1983) Effect of the extent of cure on the modulus, glass transition, water absorption, and density of an amine-cured epoxy. Appl Polym Sci 28(9):2831-2846

13. Gupta VB, Drzal LT, Rich M (1985) The physical basis of moisture transport in a cured epoxy resin system. J Appl Polym Sci 30(11):4467-4693

14. Johncock P, Tudgey GF (1986) Some effects of structure, composition and cure on the water absorption and glass transition temperature of amine-cured epoxies. Brit Polym J 18(5): 292-302

15. Van Krevelen DW, Te Nijenhuis K (2009) Properties of polymers. Their correlation with chemical structure. Their numerical estimation and prediction from additive group contributions, 4th edn. Elsevier, Amsterdam

16. Small PA (1953) Some factors affecting the solubility of polymers. J Appl Chem 3(2):71-80

17. Van Krevelen DW (1965) Chemical structure and properties of coal. XXVIII. Coal constitution and solvent extraction. Fuel 44(4):229-242

18. Hoy KL (1970) New values of the solubility parameters from vapor pressure data. J Paint Techn 42(541):76-118

19. Fedors RF (1974) A method for estimating both the solubility parameters and molar volumes of liquids. Polym Eng Sci 14:147-154

20. Barrie JA (1968) Water in polymers. In: Crank J, Park GS (eds) Diffusion in polymers, Chap. 8, Academic Press, London, pp 259-314

21. Gaudichet-Maurin E, Thominette F, Verdu J (2008) Water sorption characteristics in moderately hydrophilic polymers, Part 1: Effect of polar groups concentration and temperature in water sorption in aromatic polysulfones. J Appl Polym Sci 109(5):3279-3285

22. Courvoisier E (2017) Analysis and kinetic modeling of the thermal ageing of PEI and PEEK matrices and its consequences on water absorption. PhD thesis, Arts et Métiers ParisTech, Paris, March 2017 
23. Baschek G, Hartwig G, Zahradnik F (1999) Effect of water absorption in polymers at low and high temperatures. Polymer 40:3433-3441

24. Thominette F, Gaudichet-Maurin E, Verdu J (2008) Effect of structure on water diffusion in moderately hydrophilic polymers. Defect Diffus Forum 258(260):442-446

25. Carter HG, Kibler KG (1978) Langmuir-type model for anomalous moisture diffusion in composite resins. J Compos Mater 12(2):118-131

26. Cai LW, Weitsman Y (1994) Non-Fickian moisture diffusion in polymeric composites. J Compos Mater 28(2):130-154

27. Brethous R, Colin X, Fayolle B, Gervais (2016) Non-Fickian behavior of water absorption in an epoxy-amidoamine network. AIP Conf Proc 1736: paper no. 020070

28. Serpe G, Chaupart Verdu J (1997) Ageing of polyamide 11 in acid solutions. Polymer 38 (8):1911-1917

29. El Mazry C, Correc O, Colin X (2012) A new kinetic model for predicting polyamide 6-6 hydrolysis and its mechanical embrittlement. Polym Degrad Stab 97(6):1049-1059

30. Li L, Yu Y, Wu Q, Zhang G, Li S (2009) Effect of chemical structure on the water sorption of amine-cured epoxy resins. Corros Sci 51(12):3000-3006 